\title{
PAISAGEM DUNAR EM ÁREA URBANA CONSOLIDADA: NATUREZA, CIÊNCIA E POLÍTICA NO ESPAÇO URBANO DE FORTALEZA, BRASIL
}

\section{Dune landscape in a densely developed area: nature, science and politics in fortaleza city, Brazil}

\author{
Vanda Claudino-Sales \\ Professora do Departamento de Geografia da Universidade Federal do Ceará \\ Pesquisadora 1D do CNPq \\ Fortaleza/CE - Brasil \\ vanda.claudino@pq.cnpq.br
}

Artigo recebido para publicação em 06/04/2010 e aceito para publicação em 09/11/2010

RESUMO: Fortaleza é capital do Estado do Ceará, situado no Nordeste do Brasil. Tem $314 \mathrm{~km}^{2}$ e aproximadamente 2,5 milhões de habitantes, sendo a quinta cidade do Brasil em população e a de maior densidade demográfica, com cerca de $8.000 \mathrm{hab} / \mathrm{km}^{2}$. Do ponto de vista geoambiental, é uma cidade litorânea com $35 \mathrm{~km}$ de praias, dunas e pequenos estuários. Tais elementos naturais encontramse drasticamente degradados ou virtualmente extintas na área urbana. Quanto às dunas, que são residuais, datações realizadas nessa pesquisa indicaram idade em torno de 2.200 anos. O presente artigo caracteriza do ponto de vista natural e evolutivo o campo de dunas de Fortaleza, tipicamente formado por dunas barcanas e parabólicas. Salienta-se a evolução singular das dunas parabólicas, que iniciam barcanas e, submetidas à fixação, evoluem para a forma final. Em contexto de clima tropical tendendo à semi-aridez, as dunas colocam-se como importantes agentes catalisadores da qualidade do ambiente, por gerarem lagoas interdunares, que engendram ecossistemas costeiros aptos a abrigarem espécies da fauna continental e aquática. As dunas atuam também como captadoras de águas pluviais, alimentando os lençóis freáticos e garantindo perenidade dos rios, além de inibir cheias urbanas. O artigo trata também da grande mobilização social, realizada na perspectiva de preservar 15 ha de dunas situados em área de elevada valorização imobiliária. A luta socioambiental, vitoriosa, pela primeira vez sobressaiu-se em relação aos interesses do mercado imobiliário, resultado da interrelação entre diversos segmentos sociais, cientes e ciosos da necessidade de preservação do campo de dunas milenar "do Cocó".

Palavras-chave: Dunas costeiras. Relação Sociedade x Natureza. Movimento ambiental. Geomorfologia Costeira. Nordeste do Brasil.

ABSTRACT: Fortaleza City is the capital of Ceará State, Northeast of Brazil. It has $314 \mathrm{~km}^{2}$ of area and approximately 2,5 million people, being the fifth city of Brazil in population and the bigger demographic density $\left(8,000 \mathrm{hab} / \mathrm{km}^{2}\right)$. In the environmental point of view, it is a coastal city that exposes $35 \mathrm{~km}$ of a tropical littoral with beaches, dunes and small estuaries. In relation to the dunes, thermo-luminescence dating indicated it is has around 2,200 years. The paper characterizes the dunefields in a natural point of view, in the sense that locally, they are typically formed by barchans and parabolic forms, showing a singular evolution, from barchans to parabolics. Fortaleza city, though tropical, has a semi-arid weather tendency, and the dunes are important ecological agents: it allows the development of ponds, as well as large water tables, which make rivers permanent and forbid urban floods. Dune's tropical vegetation cover shelters species of aquatic and continental fauna. This paper 
also relates the social mobilization engendered in view to preserve 15 ha of dunes situated in a important real state area. The action was victorious, representing the first time that preservation won against urban soil speculation, as the result of an interesting relationship established between diverse social groups.

Keywords: Coastal dunes. Nature and society relationship. Greens environmental action. Coastal Geomorphology. Brazilian North-east.

\section{INTRODUCÃ̃O}

O presente artigo analisa, do ponto de vista sócioambiental, o segmento leste da cidade de Fortaleza, capital do Estado do Ceará, Nordeste do Brasil (Figura 1), em particular 15 hectares ocupados por campos de dunas fixas e entorno imediato, objeto da mobilização recente do movimento ambiental local, com vista à preservação. A área situa-se nos limites da planície de inundação do Rio Cocó (Figura 2), setor urbano extremamente valorizado do ponto de vista imobiliário.

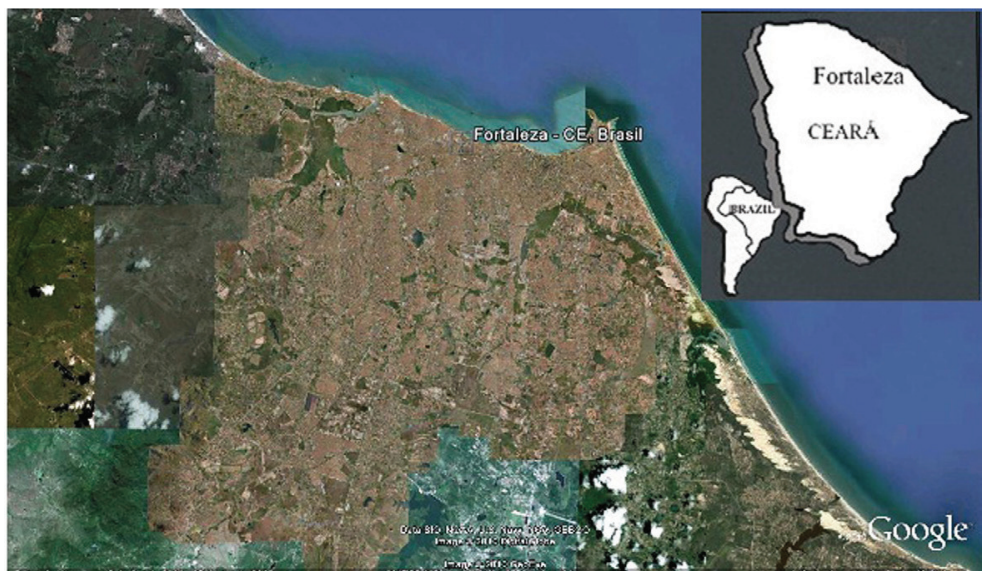

Figura 1: Localização da cidade de Fortaleza (capital do Estado do Ceará, Brasil).

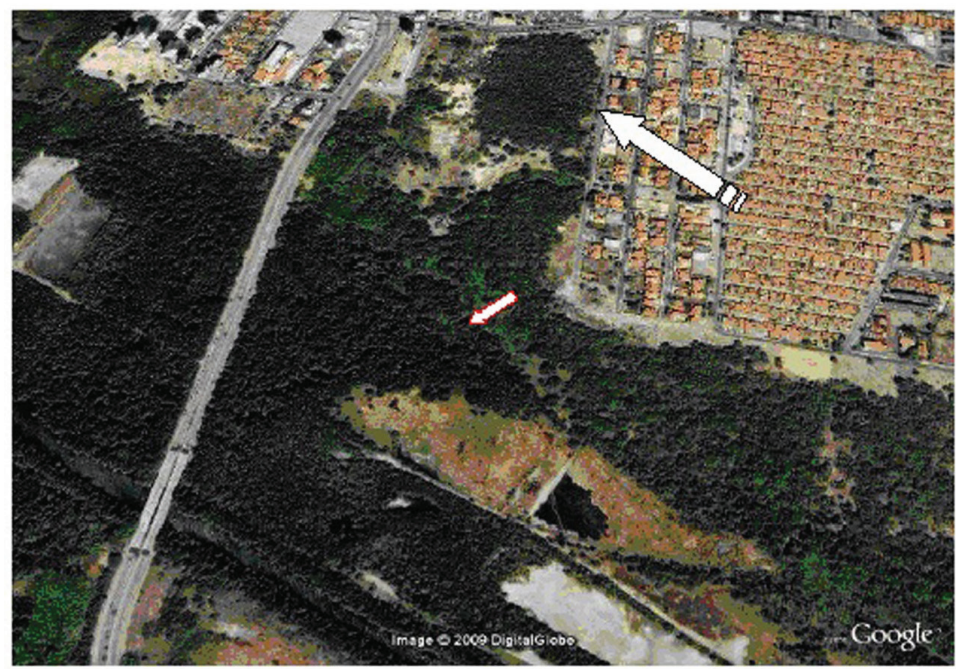

Figura 2: Localização da área de pesquisa, na planície litorânea leste da cidade de Fortaleza, Ceará, onde ocorrem relíquias de campos de dunas milenares. As dunas situam-se na margem direita do Rio Cocó, nas proximidades do bairro "Cidade 2000". 
Fortaleza tem $314 \mathrm{~km}^{2}$ de área e aproximadamente 2.600.000 habitantes (IBGE, 2008), o que a coloca como quinta maior cidade do Brasil em população e a de maior densidade demográfica, com cerca de $8.000 \mathrm{hab} / \mathrm{km}^{2}$. É também centro industrial e comercial de importância regional, representando o sétimo maior poder de compra do país (IBGE, 2008). Na última década, o turismo, internacional e nacional, vem alterando o perfil sócio-cultural local. Do ponto de vista geoambiental, é uma cidade com $35 \mathrm{~km}$ de litoral formado por praias, duans e pequenos estuários. Esse "front" litorâneo é densamente povoado, tanto por segmentos sociais abastados (litoral central e leste) quanto por população de baixa renda (setor oeste). A maior bacia hidrográfica da cidade é definida pelo Rio Cocó, que nasce na "Serra de Baturité", área montanhosa com altitudes em torno de $900 \mathrm{~m}$ situada nas adjacências imediatas de Fortaleza.

O Rio Cocó tem cerca de $49 \mathrm{~km}$ de extensão e drena quatro municípios. Dois terços do espaço urbano de Fortaleza acham-se encravado nessa bacia, particularmente no seu segmento estuarino, caracterizado por amplo bosque de manguezal. Essa área de manguezal, que conforma mais de 1.600 ha, acha-se inteiramente preservada através da criação em 1989, pelo governo estadual, e em função de ampla mobilização do movimento ecológico nos anos 1980, de um 'parque ecológico' - o Parque Ecológico do Cocó.

Apesar de preservado, o entorno do parque é sede de intensa atividade imobiliária, representando hoje, em conjunto com setores de praia, a área de maior valor imobiliário da cidade. A construção de edifícios cria grande pressão ambiental, pois parcela do entorno do parque não conta com rede de esgotamento sanitário, e as construções de edifícios de mais de 20 andares vêm gradativamente impedindo o acesso público à paisagem verde, apesar dos protestos e reinvidicações em contrário de significativa parcela da população. À margem esquerda do estuário do Rio Cocó, ocorrem vestígios ainda não completamente degradados de antigos campos de dunas, as aqui denominadas 'dunas do Cocó'.

\section{METODOLOGIA}

A presente pesquisa foi realizada a partir da análise de imagens de satélites, fotografias aéreas e mapas temáticos diversos, trabalhos de campo, compilação e análise de dados de arquivos geoambientais, análises documental, entrevistas com moradores da área em questão e pesquisa participativa e ativa, através de integração com o movimento ecológico em Fortaleza.

Dois princípios metodológicos guiaram o trabalho: o "Princípio do Uniformitarismo", que diz "o presente é a chave do passado", e permitiu considerar o contexto de dunas atuais não alteradas fora da área com os vestígios do campo de dunas do Cocó. Uma importante etapa desse procedimento envolveu a datação de sedimentos de dunas, através do método "termulominescência", realizada no Laboratório de Termoluminescência da Universidade de São Paulo. Outro conceito metodológico adjacente é o da análise geoambiental, que conduz à análise das relações entre os componentes do meio natural e social, de acordo com o proposto por Bertrand (1968). Finalmente, o trabalho tem caráter experimental, no tocante à relação sociedade $x$ natureza. Para a ilustração dos temas e locais estudados, foram utilizadas imagens do Google Earth, fotos e mapas.

\section{CARACTERIZAÇÃO GEOAMBIENTAL DA ÁREA DE ESTUDO}

A cidade de Fortaleza, do ponto de vista geomorfológico, conta com quatro principais tipos de espaços naturais:

a) Planície Litorânea: caracterizada pela ocorrência de praias e dunas móveis e semi-fixas formadas por areias quartzosas quaternárias, comportando lagoas interdunares;

b) Tabuleiros Costeiros, o de maior representatividade espacial, que se acha recoberto por dunas quaternárias, sobre os quais a maior parte da cidade de Fortaleza foi edificada. Os tabuleiros são sustentados por sedimentos de idade terciária a quaternária (a Formação Barreiras), os quais se apresentam extremamente planos;

c) Pedimento cristalino: com expressão limitada a sul, sudoeste e sudeste da cidade, esse compartimento geomorfológico é representado pelo 
afloramento de rochas cristalinas antigas (pré-cambrianas), aplainadas, de forma a não propiciar ruptura na topografia local, compondo a chamada 'depressão sertaneja";

d) Planícies fluviais, que dissecam indistintamente o pedimento cristalino, os tabuleiros e a planície litorânea. Na planície litorânea, as planícies fluviais transformam-se em planícies flúvio-marinhas com manguezais, os quais já foram erradicados pela urbanização nas desembocaduras de pequena dimensão, ocorrendo apenas na planície do Rio Ceará, a oeste, e do Rio Cocó, a leste.

Esses domínios geomorfológicos definem a cidade como essencialmente sedimentar. Tal fato implica na existência, do ponto de vista natural, de elevada taxa de infiltração de águas pluvias, permitindo a ocorrência, em função das características pluviais, de rico lençol freático, o qual alimenta rios, riachos e lagoas durante os meses de estiagem. A altitude média da cidade de Fortaleza é de $21 \mathrm{~m}$, o que a coloca no âmbito de terrenos baixos. Alguns setores apresentam menores altitudes, correspondendo às áreas ocupadas pelos recursos hídricos. As dunas, no entanto, sejam as móveis atuais ou as fixas antigas, representam cômoros de maior expressão altimétrica, com valores acima de 20 metros, os quais rompem a homogeneidade da topografia, como pode ser avaliado na Figura 3.

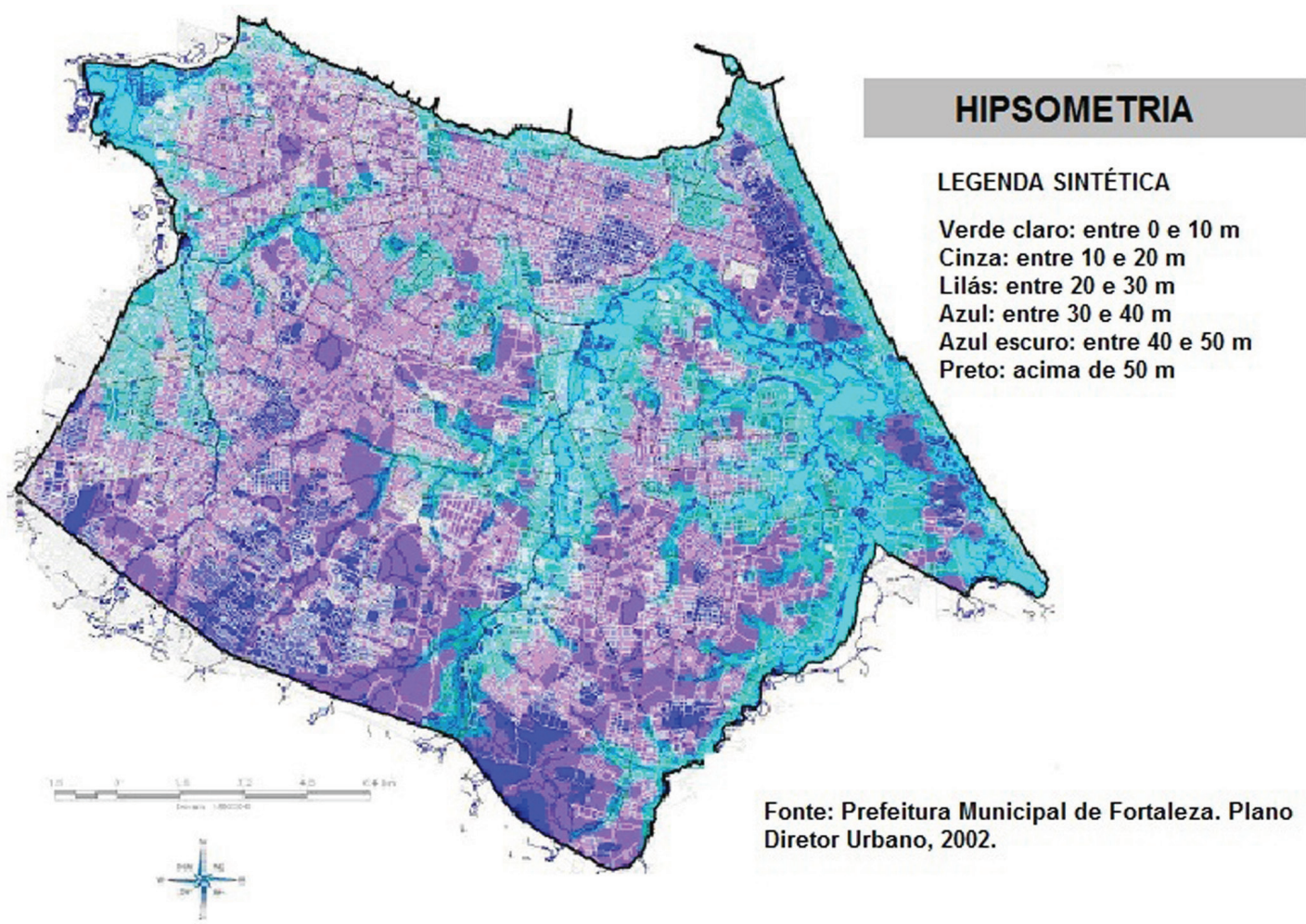

Figura 3: Altitudes de Fortaleza. Verificar que o setor leste da cidade, onde se situa a área de estudos,

Fortaleza era colonizada por vegetação adequada às condições ambientais. Na Planície Litorânea, ocorria vegetação pioneira, fixadora de areias de dunas e praias. Nos tabuleiros, a rica vegetação exibia espécies típicas de zona costeira, associadas com algumas espécies comuns à zona de sertão (vegetação xerófita, denominada caatinga), a qual se acha hoje presente apenas na forma de resíduos isolados, tais como no campus universitário da Universidade Federal do
Ceará. Nos segmentos flúvio-marinhos das bacias hidrográficas, ocorrem manguezais. A elevada antropização da área coloca hoje em evidência a ocorrência de espécies vegetais não nativas desses domínios, de forma rarefeita. A vegetação que apresenta menor presença de espécies forasteiras, exóticas, corresponde ao manguezal, presente nas planícies flúvio-marinhas dos rios Cocó e Ceará. A baixa densidade vegetacional de Fortaleza é ilustrada pela Figura 4. 


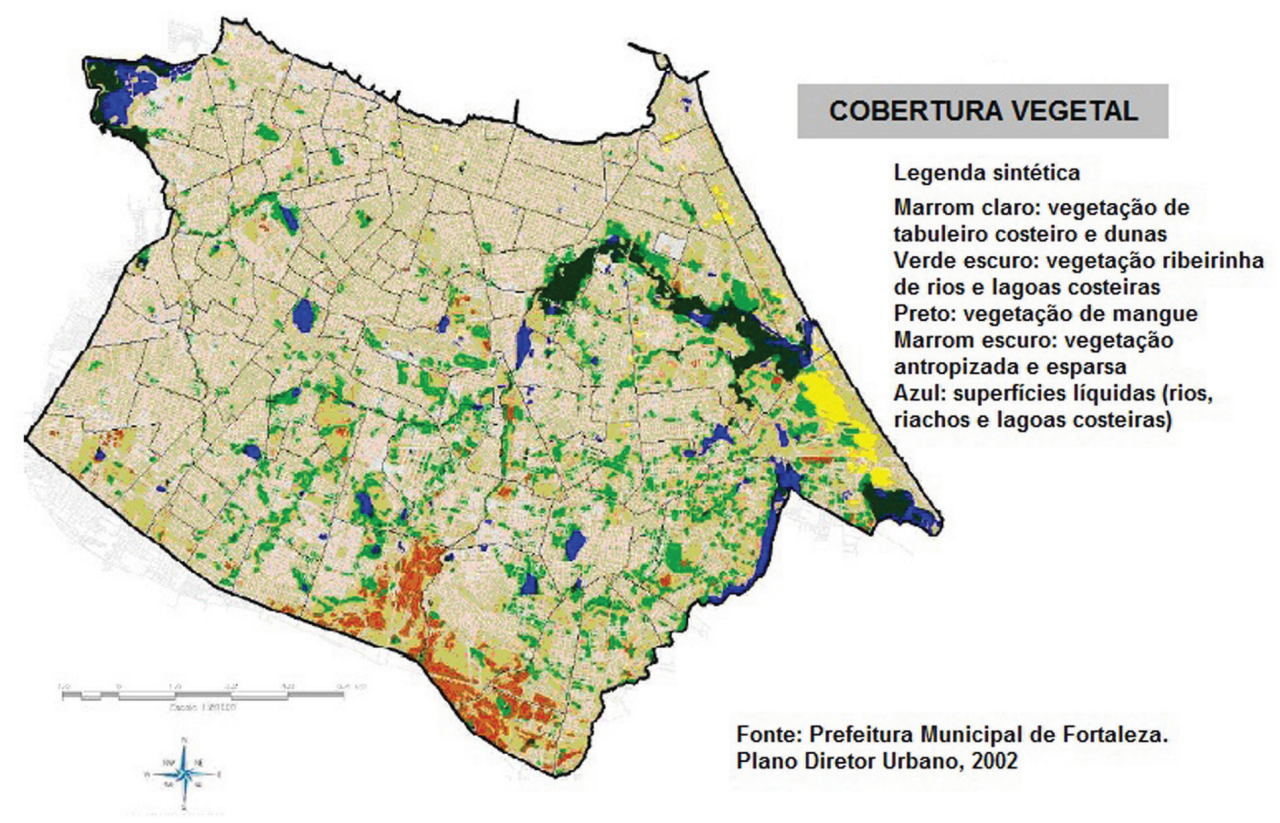

Figura 4: Cobertura Vegetal em Fortaleza.

A área de estudo acha-se recoberta pela formação florestal costeira que recobre tabuleiros costeiros e dunas.

Fortaleza apresenta um clima tropical úmido com estação seca bem definida. As médias pluviométricas são elevadas, mas há irregularidade da distribuição das precipitações ao longo do ano, traduzida na concentração de cerca de $92 \%$ do total das chuvas no primeiro semestre. Dado o caráter tropical, sub-equatorial da cidade, as temperaturas médias são elevadas, situadas em valores mensais médios que vão de 25 a 28 graus, o que também implica em elevada taxa anual de evapotranspiração real, que é da ordem de $997 \mathrm{~mm}$ : tal fato implica em existência de acentuado déficit hídrico anual no segundo semestre do ano, da ordem de $611 \mathrm{~mm}$ (CLAUDINO-SALES; PEULVAST, 2002). Assim, há estresse no ambiente, implicando em comportamento climático com tendência à semi-aridez. Tal fato é acentuado pela existência efetiva de condições climáticas semi-áridas na hinterlândia, que transforma o Nordeste brasileiro em uma exceção climática, por ser intertropical, sub-equatorial, porém seco

\section{Caracterização geoambiental das dunas do Cocó}

Dunas costeiras são formas de relevo criadas pela ação do vento, que mobiliza areias disponíveis nas praias e as acumulam na forma de cômoros de alturas variadas, no interior da zona costeira. Elas podem ser móveis (com migração contínua das areias), fixas (associadas à presença de cobertura vegetal costeira, que imobiliza os sedimentos) e semi-fixas (com encostas ou dorsos parcialmente móveis, parcialmente fixos). As dunas do Cocó são semi-fixas, do tipo "parabólicas".

As dunas parabólicas têm forma em meialua, ou croissant, com braços dispostos longitudinalmente à direção do vento principal, antecedendo o corpo principal da duna (nesse sentido, são opostas às dunas barcanas, que também têm forma em croissant, porém com segmentos laterais - os braços - posteriores ao corpo principal da duna (Figura 5). Tais tipos de dunas potencializam a formação de ecossistemas paticulares, pois no seu interior comumente ocorrem lagoas, formadas pela deflação, que evolui com o vento removendo areias até atingir o nível do lençol freático, o qual então aflora. As dunas parabólicas existentes no segmento nordeste de Fortaleza são do tipo parabólicas 'hairpin' - literalmente, parabólicas 'grampo-decabelo". Tais feições são assim denominadas em razão da grande expressão espacial que apresentam os braços da duna, que se prolongam por várias centenas de metros, até quilômetros, em direção ao interior do continente: os sedimentos retirados da 
zona central pela deflação acumulam-se no front da duna, promovendo assim a sua contínua migração em direção ao interior da zona costeira (Figura 6).
As dunas parabólicas no Nordeste e no Estado do Ceará apresentam um processo evolutivo bastante singular e complexo. Elas derivam em geral de

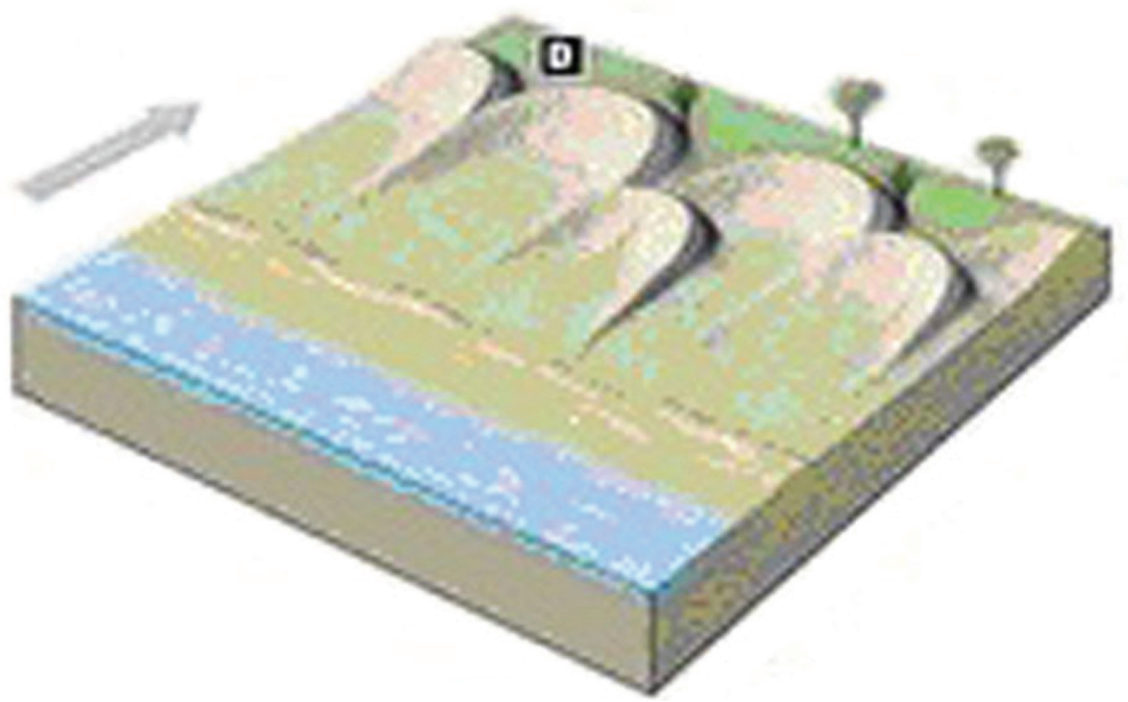

Figura 5: Geometria genérica de uma duna parabólica. Seta à esquerda indica a direção do vento principal.

A letra D indica o front da duna. Entre os braços, na área de maior deflação, ocorrem lagoas interdunares. Fonte: DAVIS, 2006.

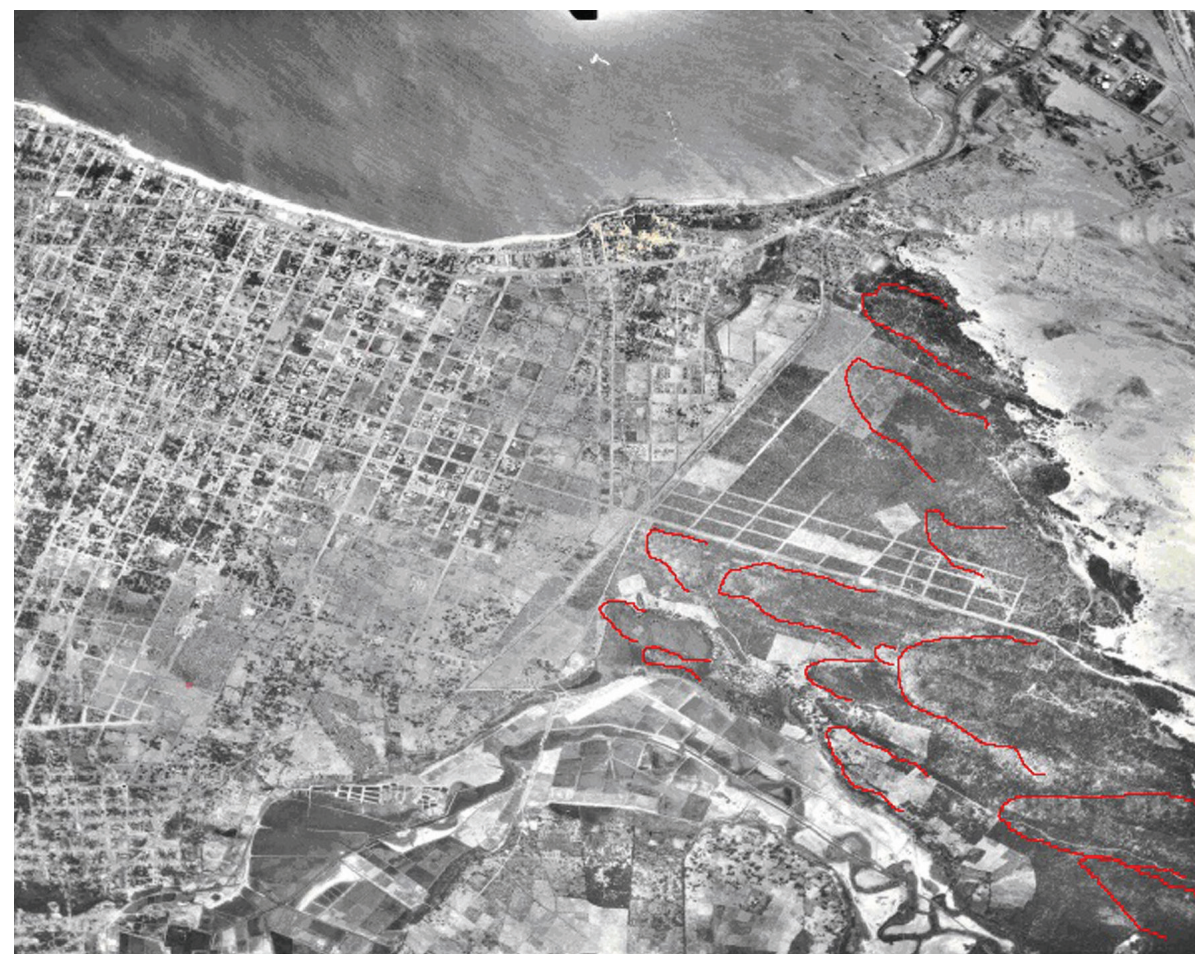

Figura 6: Campo de dunas parabólicas ‘hairpin’ no segmento leste de Fortaleza. As dunas estão identificadas através das linhas em vermelho. Fonte: Foto aérea da empresa Cruzeiro do Sul, de 1968. 
mudanças morfológicas, engendradas por mudanças climáticas, pelas quais passam as dunas barcanas, que representam formas dunares bem mais frequentes na zona costeira cearense. Em função de mudanças climáticas naturais, que foram comuns ao longo da história geológica recente, a cobertura vegetal - que tende a se desenvolver mais em épocas úmidas e assim fixar dunas, e a se desenvolver menos em épocas mais secas, assim permtindo a migração de dunas -, são os elementos finais responsáveis por essas mudanças morfológicas (DURAN; HERRMANN, 2006). Tal processo pode ser apreciado a partir da análise da Figura 7.
A mudança de forma, de barcanóide e barcana para parabólica, resulta, em outras palavras, de processo de estabilização de dunas móveis, o qual, ao seu término, implica na geração de um novo ecossistema - de uma nova fauna e flora - nas áreas de ocorrências (TSOAR et al, 2009). A idade das dunas do Cocó (Figura 8) - isto é, a idade de fixação das areias - foi estimada, a partir de datações por termoluminescência $(\sim 1 \mathrm{~m})$, para fins dessa pesquisa, como da ordem de 1,900 +/-250 anos. Essa datação representa a primeira, em termos do campo dunar de Fortaleza, e afina a obtida anteriormente na Praia do Pecém (40 km de Fortaleza) por Maia (1998) e no Porto das Dunas por Tsoar et al (2009), que indicaram idade entre 1.700 anos.

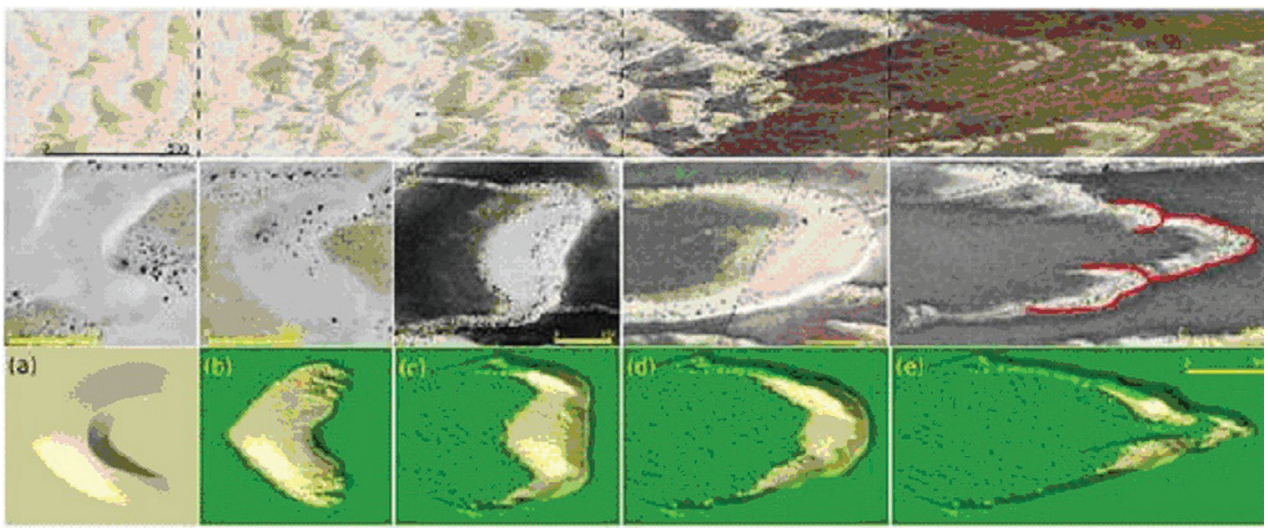

Figura 7: Mudança de forma de dunas costeiras no Nordeste do Brasil. No topo, em terrernos naturais, um campo de barcanóides evolui para parabólicas hairpin em segmento do litoral do Maranhão. No centro e abaixo, exercício de modelização mostrando as etapas evolutivas de transformação de dunas barcanas em parabólicas, em função de mudanças na cobertura vegetal, resultantes de mudanças climáticas ocorridas na história geológica recente, e tal como ocorre na região costeira do Ceará. Fonte: DURAN; HERRMANN, 2006. Autorização de uso da figura gentilmente concedida pela American Physical Society - APS. WebSite do artigo: http://prl.aps.org/abstract/PRL/v97/i18/e188001.

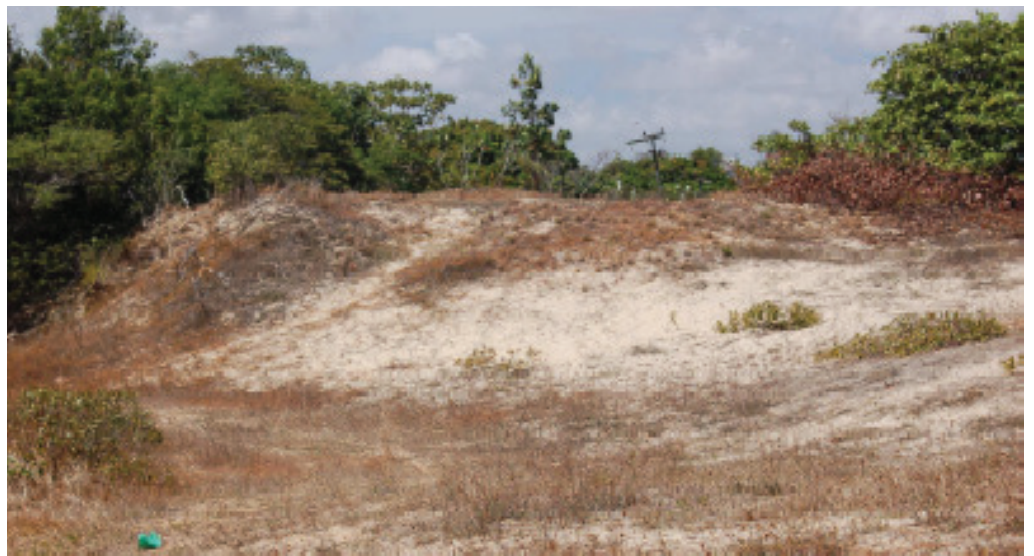

Figura 8: Dunas do Cocó. Resquícios do campo de dunas parabólicas semi-fixo na margem leste do Rio Cocó. Foto de novembro de 2008. 
Como elementos constituintes de campos de dunas parabólicas, ocorrem lagoas interdunares perenes e intermitentes, olhos d'água e áreas alagadas e alagáveis. O grau de alteração antrópica do terreno em análise não permite mais identificar toda a riqueza dos recursos hídricos superficiais que caracterizam esse tipo de sistema dunar. Essa riqueza pode, no entanto, ser avaliada a partir da visualização de dunas semelhantes existentes ainda hoje no litoral de Lagoinha, Ceará (Figura 9).
Ainda assim, a partir de trabalhos de campo, foi possível averiguar a existência de olhos d'água, pequenos córregos de expressão espacial restrita e áreas de baixio, local de formação de lagoas interdunares intermitentes (Figura 10). As dunas prabólicas hairpin e seus recursos hídricos jamais voltarão a se desenvolver na zona litorânea de Fortaleza, em função da inexistência de espaço para acomodação de areias nos dias atuais.

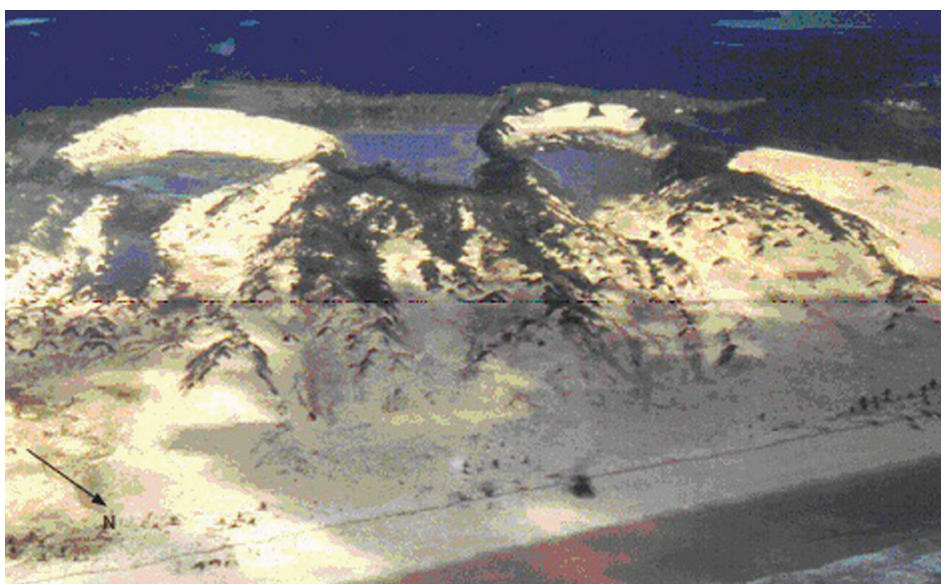

Figura 9: Dunas parabólicas "hairpin” conservadas na praia da Lagoinha. Essa paisagem dunar, com formas expondo mais de $3 \mathrm{~km}$ de extensão, apresenta grande riqueza de coleções de águas superficiais, como lagoas interdunares, entre os braços das dunas, considerando que a deflação faz aflorar o lençol freático superficial. Essa era a paisagem típica das dunas parabólicas hairpin de Fortaleza, antes da quase completa destruição dos campos dunares ali existentes de forma natural. Foto de abril de 1996.

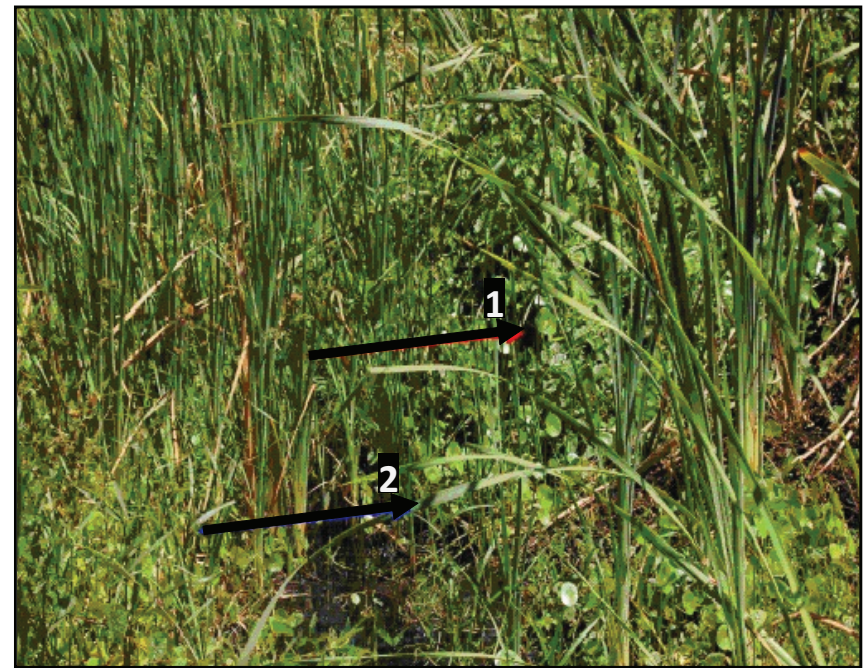

Figura 10: Lagoa interdunar assoreada. As condições hidromórficas são indicadas pela presença das macrófitas Eichornia crassipes (o aguapé: seta 1) e capim d'água (Paspalidium geminatum, seta 2), além de outras vegetações aquáticas típicas de áreas degradadas. O setor corresponde à uma lagoa interdunar perene, hoje completamente assoreada, poluída e asfixiada por vegetação aquática invasiva, como resultado de alterações antrópicas de elevada magnitude, ocorridas sobretudo ao longo da década de 1990. Foto de novembro de 2008. 
$\mathrm{Na}$ realidade, considerando-se o atual ritmo e forma de ocupação da zona costeira regional com grandes complexos turísticos e construções sem critérios ambientais, pode-se seguramente considerar que tais relevos jamais voltarão a ser produzidos em toda a extensão da zona costeira do Nordeste do Brasil. Em adição, a continuar esse ritmo de ocupação, as formas existentes fatalmente desaparecerão, perdendo-se para sempre paisagens naturais que a história geológica demanou milhares de anos para construir.

\section{Área de Dunas Móveis}

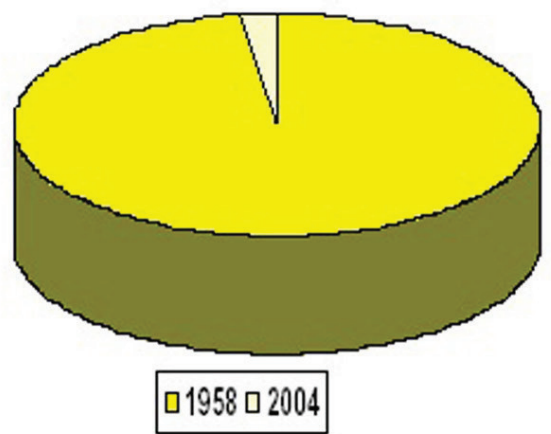

SEGMENTO LESTE DE FORTALEZA: ÁREA URBANA CONSOLIDADE COM DUNAS RESIDUAIS

Fortaleza, quando da chegada dos portugueses nos anos 1.500, era um só campo de dunas de grande expressão. Mas, a cidade cresceu, do ponto de vista urbano, às custas da destruição do seu patrimônio e paisagens naturais. Riachos, córregos, cobertura vegetal nativa, campos de dunas e praias, foram simplesmente

\section{Área de Dunas Fixas}

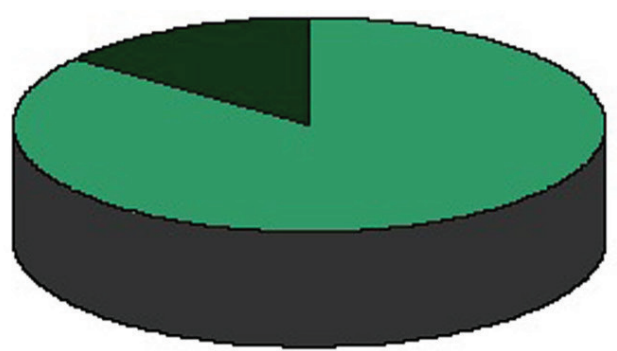

$1958 \square 2004$

Figura 11: Alteração na cobertura de dunas de Fortaleza. À esquerda- amarelo escuro (fatia maior): ano 1958; amarelo claro (fatia menor): ano 2004. À direita: verde claro (fatia maior), ano 1958; Verde escuro (fatia menor), ano 2004. Fonte: Pinheiro, 2009.

desaparecendo ao longo do processo evolutivo histórico de sua malha urbana. Nesse processo, o campo de dunas foi sendo reduzido paulatinamente. Já nos anos 1970, praticamente restavam os setores da Praia do Futuro e a área nordeste da cidade, onde se situa o terreno em análise, com remanescentes de terrenos dunares não degradados. A partir da década de 1970, a destruição ampliou-se, através de desmatamento e terraplanagem, visando a construção de vias de circulação, edifícios residenciais e até uso das areias na construção civil. A Figura 11 demonstra a erradicação do espaço urbano desses relevos.

Apesar da diminuição dramática da paisagem dunar, que coloca as dunas em Fortaleza em situação de remanescentes residuais, a destruição dos terrenos de dunas continua ocorrendo. Assim é que o terreno em tela foi objeto de profunda agressão ao final do ano de 2008, de forma clandestina, como tentativa de desobediência à Resolução 303, do Conselho Nacional do Meio Ambiente - CONAMA, que colocou essas feições como Áreas de Preservação Permanente-APP a partir de 2002 (Figura 12). O objetivo era transformar a área em solo urbano, na perspectiva de construção de condomínio residencial como permitia a legislação urbana anterior a 2002.

A destruição das dunas em Fortaleza vem colocando a cidade em contexto de permanente estresse ambiental, dado o elevado grau de impermeabilização dos terrenos que essa prática impõe. A impermebialização também diminui o reabastecimento dos lençóis subterrânos, e já é notável, em álguns setores de Fortaleza, a diminuição dos espelhos d'água de lagoas, tais como as Lagoas do Papicu e Lagoa da Precabura, por diminuição da alimentação normal a partir do subsolo. 


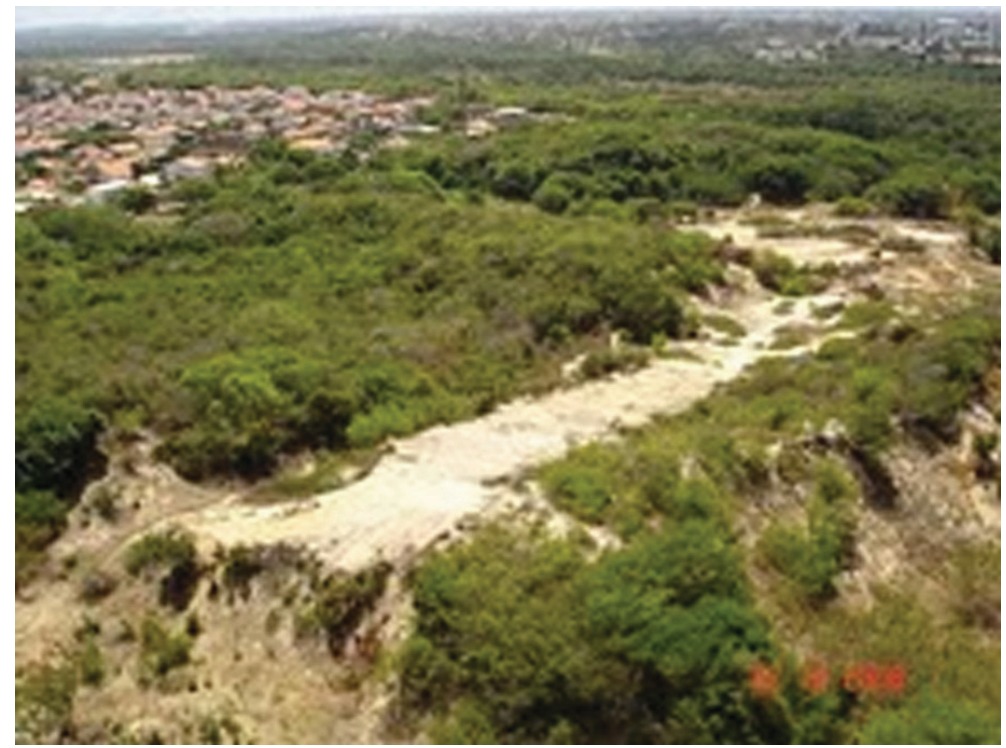

Figura 12: Destruição das dunas do Cocó. A foto ilustra a área após a destruição realizada pelos tratores de empreteiras, em dezembro de 2008. Foto: Blog "Salvem as dunas do Cocó".

Os recursos hídricos estão assim diminuindo, desaparecendo ou sendo amplamente degradados.

Considerando o fato da pequena altitude dos terrenos locais e a ausência de desnivelamentos tográficos expressivos, a ocorrência de enchentes urbanas vem sendo, então, frequente. Tais fatos implicam em desconforto urbano e prejuízos materiais, tanto para a população quanto para as estruturas urbanas (avenidas esburacadas, calçadas danificadas, galerias pluviais atulhadas por sedimentos e resíduos urbanos, alagamentos causadores de problemas de saúde pública, acúmulo e/ou distribuição de lixo urbano). Tais prejuízos acabam sacrificando a população duplamente: geram incômodos enquanto estão ocorrendo e há perda de investimentos em outros setores sociais, como educação, saúde, transportes, que terão que ser re-direcionados para a recuperação do que foi danificado pelas enchentes.

A retirada da cobertura vegetal em Fortaleza também é fator de extrema preocupação. O Inventário Ambiental de Fortaleza (PMF, 2002) indicou que entre os anos 1968 e 2002, a cidade perdeu cerca de $70 \%$ de sua cobertura natural. Isso coloca o fortalezense em contexto de baixa qualidade de vida, fato que é reformaçado por outra realidade: existe menos de $3 \mathrm{~m}^{2}$ de área verde por habitante na cidade. A Organização Mundial da Saúde indica, no entanto, a existência de
$12 \mathrm{~m}^{2}$ por habitante, para a existência de uma boa qualidade de vida. Várias cidades brasileiras já atingiram esse patamar, mas Fortaleza, nestes termos, só faz regridir.

Tais mudanças no quadro ambiental traduzem-se por modificação acentuada no clima urbano, e ilhas de calor vêm sendo detectadas em alguns bairros (MOURA, 2008). A temperatura vem também aumentando nos últimos anos, ocorrendo em algumas áreas valores estáveis de aumento da ordem de quase 4 graus centígrados (MOURA, 2008). Para se ter uma idéia da gravidade dessa situação, as modelizações do Painel Intergovenamental de Mudanças Climáticas - IPPC, da ONU, que vem realizando prognósticos e criando cenários futuros em termos de aquecimento global, indica um aumento da ordem de 1 grau para os próximos decênios, o que já implica em desastres ambientais. Ora, Fortaleza já apresenta valor três vezes maior do que o apontando para a média global pelo IPCC.

\section{NATUREZA, CIÊNCIA E POLÍTICA PELA PRESERVAÇÃO DAS DUNAS DO COCÓ: CON- CLUSÕES}

O movimento ambiental em Fortaleza atua há cerca de 30 anos. Ao longo desse período, mesmo comportando algumas oscilações quanto à participação e ação, sempre foi agente mobilizador e catalisador 


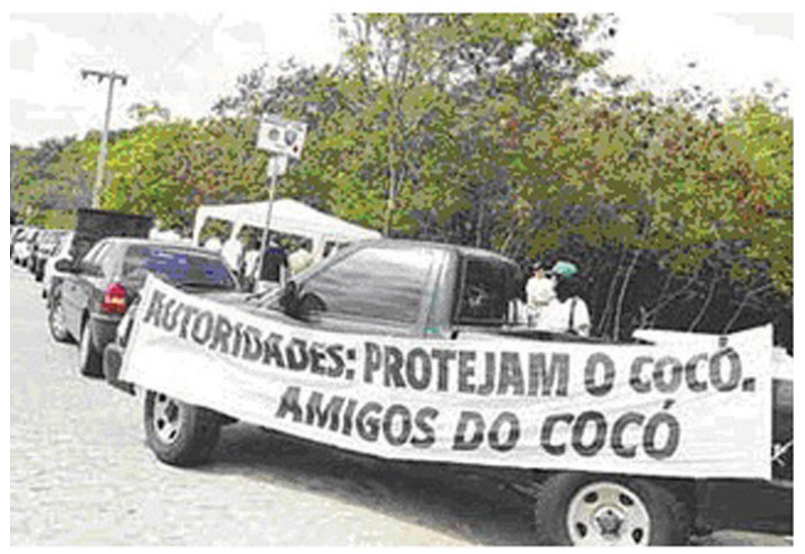

Figura 13: Mobilização em prol da proteção das dunas do Cocó. Passeata realizada visando chamar a atenção da população de Fortaleza para a necessidade de preservação das dunas do Cocó, ao mesmo tempo em que visou denunciar a perseguição e os desmandos associados com o processo de discussão e votação do projeto de preservação desse campo residual de dunas na Câmara dos Vereadores de Fortaleza. Em 19 de julho de 2009. Fonte: Blog "Salvem as Dunas do Cocó”. Disponível em: <http://salvemasdunasdococo. blogspot.com>.

de cidadania. O movimento acumula muitas vitórias, mas também várias derrotass frente aos governos e interesses privados - mas, mesmo nesses momentos, o movimento ecológico teve o papel fundamental de propiciar discussões e reflexões, criando e ampliando uma cultura ambiental na cidade.

Nova etapa dessa luta socioambiental iniciou em outubro de 2008, quando grupos de moradores do entorno das dunas do Cocó, sobressaltados pela movimentação nos terrenos por empresas da construção civil, organizaram-se em torno do recém criado movimento "Salvem as Dunas do Cocó" e articularam-se com as entidades do movimento ambiental. A existência de ambientalista e ao mesmo tempo pesquisadora da área em questão permitiu a produção de um parecer técnico-científico, que foi encaminhado por vereador e também ambientalista à Câmara dos Vereadores, na forma de projeto de lei, propondo a criação de uma ARIE - Área de Relevante Interesse Ambiental, á luz da legislação brasileira em vigor. AARIE é uma unidade de conservação que não implica em desapropriação dos terrenos preservados por lei, mas os disponibiliza para efeitos de preservação ambiental.

Como parte do processo legislativo, o projeto e seu parecer foram inicialmente analisados pela Comissão de Constituição e Justiça, que o aprovou. O segundo passo, a aprovação na Comissão do Meio Ambiente, produziu inúmeros percalços e constrangimentos, comportando arguição quanto à veracidade $\mathrm{e}$ competência dos documentos. Vários integrantes do movimento ambiental sofreram, nesse período, tentativa de cerceamento, através de ameaças judiciais, ainda em curso. Porém, as denúncias realizadas nos meios de comunicação e a mobilização pública (Figura 13) produziram efeitos, e assim, em 28 de junho de 2009, o projeto foi colocado em votação, sob forte pressão do movimento sociail e solicitação assinada por mais de duas mil pessoas. Os vereadores, assim, dobraram-se às evidências: a cidade queria a preservação das dunas do Cocó. Pela primeira vez, como resultado, foi criada por ato legislativo uma unidade de conservação, a partir do voto favorável de ampla maioria.

O processo parecia encerrado, mas, por iniciativa de vereador contrário ao projeto, o caso foi levado à justiça comum, sob argumento de ferir leis antigas. Tal iniciativa produziu dura mas curta batalha judicial, com liminares favoráveis e contrárias, até serem esgotados os instrumentos judiciais, que apontaram, ao final, a necessidade de envio do projeto aprovado para sanção da prefeita. Ainda coube espera de exatos quinze dias - prazo legal - para que tal sanção ocorresse, mas ela finalmente foi realizada, por iniciativa da Prefeita Luiziane Lins, em 6 de outubro de 2009, ficando definitivamente proibida a construção de qualquer empreendimento na área.

A cidade celebrou a vitória de várias formas. Todos os meios de comunicação deram destaque à preservação das dunas. O movimento ambiental, por sua 
vez, comemorou através de nota pública, nos seguintes termos: "essa importante vitória é uma vitória não apenas do movimento ambientalista, mas do povo de Fortaleza. Ganhamos no Legislativo, no Executivo e no Judiciário. O verde e a natureza estão de parabéns. Com a aprovação definitiva deste projeto a cidade irá respirar melhor". O editorial do jornal O POVO do dia 07 de outubro demonstra bem o espírito que tomou conta da sociedade civil organizada em Fortaleza, com o processo de preservação das dunas do Cocó: "No dia 18 de julho passado a Câmara Municipal, numa votação histórica, havia aprovado o projeto, depois de intensos debates no plenário. A divergência é própria do sistema democrático, sobretudo, em iniciativas desse porte, que envolve fortes interesses econômicos. O que estava em jogo era o embate entre dois modelos de desenvolvimento: o tradicional, que põe acento principal no aspecto econômico, e o sustentável -, que procura combinar crescimento econômico com a preservação do meio ambiente".

No contexto exposto, fica claro que ciência, política e luta social produziram um resultado positivo para a melhoria da qualidade de vida na cidade de Fortaleza. A expectativa agora é de que os órgãos públicos e os governantes entendam a mensagem explícita transmitida pelo conjunto da sociedade e transformem em realidade material e objetiva o que foi acaba de ser conquistado na dimensão legal.

\section{AGRADECIMENTOS}

A pesquisa sobre as dunas de Fortaleza é financiada pelo CNPq (Conselho Nacional de Desenvolvimento Científico e Tecnológico). Agradecemos a Profa. Dra. Sônia Tatumi, pela datação da duna do Cocó no Laboratório de Termoluminescência da USP. Pela mobilização visando a preservação ambiental em Fortaleza, agradecemos e parabenizamos os ambientalistas João Alfredo Melo (também vereador pelo PSOL), Nayana Freitas, Arnaldo Fernandes, Vólia Barreira, Josael Jairo, João Saraiva, Laércio Avelino, Marília Brandão, Marcelino Pequeno e Luis Cruz Lima. Agradecemos ainda à Universidade Federal do Ceará, através do Magnífico Reitor Jesualdo Pereira, do Procurador Paulo Albuquerque e do Chefe do De- partamento de Geografia, Francisco Amaro Alencar, bem como à ADUFC (Associação dos Docentes da Universidade Federal do Ceará), SBPC (Sociedade Brasileira para o Progresso da Ciência) e Associação dos Geógrafos Brasileiros-seção Fortaleza, pelo apoio ofertado diante das ameaças judiciais e administrativas, ora em curso. Agradecemos também aos meios de comunicação, em particular aos jornalistas Daniel Fonseca, Eliomar de Lima, Agostinho Gósson e Paulo Mamede. Agradecemos ainda aos alunos dos cursos de Geografia e Ciências Sociais da Universidade Federal do Ceará e da Universidade Estadual do Ceará, que participaram do processo. A autora também agradece ao revisor anônimo da revista "Sociedade e Natureza", pelas excelentes sugestões apresentadas quando da leitura do texto inicial.

\section{REFERÊNCIAS}

BERTRAND, G. Paisagem e Geossistema. Cadernos de Ciência da Terra, USP, 18p. 1968

CLAUDINO-SALES, V.; PEULVAST, J. P. Dunes generations and ponds in the coast of Ceará State (Northeast Brazil). In: R. ALLISON (Org.), Applied Geomorphology: Theory and Practice. 1 ed. London: John Wiley \& Sons, v. 1, 2002. p. 443-460.

DAVIS, R. Evolving coasts. Berlin: Spring-Verler, 2006.

DURAN, O.; HERRMANN, H.J. Vegetation against Dune Mobility. Physical Review Letter, v. 97, p. 188001. 2006.

IBGE. Instituto Brasileiro de Geografia e Estatística. Sinopse censitária do Brasil. Rio de Janeiro: IBGE, 2008.

MAIA, L. P. Procesos Costeros y Balance Sedimentário ao lo largo de Fortaleza (NE-Brasil). Implicaciones para una gestão adecuada de la zona costera. 1998. 192f. Tesis (Doctoral en Geología) - Universitad de Barcelona, 1998.

MOURA, M. O. O clima urbano de Fortaleza sob o 
nivel do campo térmico. 2008. Dissertação (Mestrado em Geografia) - Departamento de Geografia, UFC. 2008.

PINHEIRO, M. V. Evolução geohistórica das dunas de Fortaleza. 2009. 210p. Dissertação (Mestrado, em Geografia) - Departamento de Geografia da UFC, 2009.

PMF. Prefeitura Municipal de Fortaleza. Inventário Ambiental de Fortaleza. 2002.

TSOAR, H.; LEVIN, N.; PORAT, N.; MAIA, L. P.; HERRMANN, H.; TATUMI, S.; CLAUDINOSALES, V. The effect of climate change on the mobility and stability of coastal sand dunes in Ceará State (NE Brazil). Quaternary Research, v. 71, n. 2, p. 217-226, 2009. 